\title{
Reaction Time in Masked Semantic Priming Experiments with Persian vs. English Primes
}

\author{
Ali Akbar Ansarin a, Solmaz Saeeidi Manesh a * \\ a University of Tabriz, English Department, Tabriz, Iran
}

Received 30 April 2016 | Received in revised form 26 August 2016 | Accepted 30 November 2016

\begin{abstract}
The psycholinguistics field has long been concerned with bilinguals' mental lexicon; the way bilinguals restore words in their mental lexicon and the way they retrieve them. So the representation of languages in bilingual minds has been explored by many researchers within the field. And different researches have led to different results. The more information regarding bilingual memory is acquired; better image would be constructed about this knowledge representation. The present study is an attempt to investigate if bilinguals share semantic features of their L1 and L2 using masked semantic priming paradigm. In masked priming, the primes were presented for a very short time and they were covered by a mask or a row of hash marks (\#\#).Target-prime pairs addressed in the study were semantically related words in two experiments. In both of the experiments target words were in English, but the primes were in Persian in the first experiment and in English in the second. Reaction time of sixty Persian-English bilinguals for these prompts was measured by DMDX software. Results showed that semantic priming effect under masked conditions could not find in any of the experiments. The findings indicate that bilinguals have shared semantic representation for two languages with different scripts only for the cognate words. Results suggest that using semantically related words, for non-cognate words, in the process of language teaching is useful in advanced proficiency levels.
\end{abstract}

(C) 2017 EJAL \& the Authors. Published by Eurasian Journal of Applied Linguistics (EJAL). This is an open-access article distributed under the terms and conditions of the Creative Commons Attribution license (CC BY-NC-ND) (http://creativecommons.org/licenses/by-nc-nd/4.0/).

Keywords: Bilingual memory; Priming; Semantic priming; Masked semantic priming; Lexical decision

\section{Introduction}

Priming is an implicit memory effect in which exposure to one stimulus influences a response to another stimulus. Various experiments supported the theory that activation spreading among related ideas was the best explanation for the facilitation observed in the lexical decision task (Schvaneveldt and Meyer, 1973). The priming paradigm provides excellent control over the effects of individual stimuli on cognitive processing and associated behavior because the same target stimuli can be presented with different primes. Thus differences in performance as a function of differences in priming stimuli must be attributed to the effect of the prime on the processing of the target stimulus.

\footnotetext{
* Solmaz Saeeidi Manesh. Tel.: +98 9144195428

E-mail address: s_saidi_m@yahoo.com

http://dx.doi.org/...
} 
Masked priming paradigm is the most frequently used method for studying subliminal processing (Merikle, 2000). The extent to which unconscious information can influence behavior has been a topic of considerable debate throughout the history of psychology. Most researchers found significant priming in their analyses, indicating that unconsciously presented information can influence behavior (e.g., Williams, 1994; Grainger \& Frenk-master, 1998; Jiang \& Forster, 2001; Perea, Dunabeitia \& Carreiras, 2008; Schoonbaert, Duyck, Brysbaert \& Hartsuiker, 2009; Zhao, Li, Liu, Fang \& Shu 2011; Chen, Zhou, Gao \& Dunlap, 2014).

The advantage of masked priming is that it allows one to investigate the effect of a particular prime-target relationship without participants' awareness of the manipulation, so that they cannot develop response strategies. Thus this technique is a relatively pure way to probe into the machinery of lexical processing (Forster \& Davis, 1984).

The theory underlying masked priming paradigm is subliminal psychology according to which unconsciously perceived stimuli can affect one's decisions, thoughts, etc. (Merikle, 2000). Though visual subliminal message in masked priming is presented only for a very brief period of time, it does not reach consciousness level; though we do not see it, our brain processes it. The evidence that the stimulus in masked priming affects later decisions is already confirmed by behavioral and neuropsychological evidence.

The representation of languages in bilingual minds has been explored by many researchers, using different priming paradigms, which has led to different results. Masked priming was first developed by Forster and Davis (1984). They investigated repetition priming and frequency attenuation in lexical access. In the first experiment, which was under unmasked condition, they found that priming effect was greater for low frequency words than for high frequency words. They attributed the unexpected result to episodic memory trace (Episodic memory is the name given to the capacity to consciously remember personally experienced events and situations. It is one of the major cognitive capacities enabled by the brain). In order to eliminate the episodic trace, the authors presented the prime for a very short stimulus-onset asynchrony (SOA). In other words, they masked the prime. Under masked paradigm, the expected frequency attenuation effect was obtained.

In one of the first studies, Bourassa and Besner (1998) investigated priming effect for semantically related pairs. They included two types of pairs in their study. Half of the words were preceded by related primes, and half by nonwords. For example, the word cat was once preceded by dog and once by deg. The observed priming was greater for the related words than for the nonwords.

In a recent study, Sanchez-Casas, Ferre, Demestre, García-Chico, and García-Albea (2012) aimed to investigate the pattern of semantic priming effects, under masked and unmasked conditions, in the lexical decision task, manipulating type of semantic relation and associative strength. Three different kinds of word relations were examined in two experiments: only-semantically related words and 
semantic/associative related words with strong and weak association strength. The results showed that there were masked priming effects with strong associates, but no evidence of these effects was found with weak associates or only-semantic related word pairs. When the prime was presented unmasked, the three types of relations produced significant priming effects and they were not influenced by association strength.

A large number of the studies have considered cognates i.e., words that share orthography and phonology, and noncognates. In most of the studies, researchers could find priming effect for cognates. But for noncognates the findings are not always consistent especially when the languages have different scripts. For example, De Groot and Nas (1991) failed to find across languages semantic priming under masking paradigm. The study was an investigation of associative semantic priming effect using lexical decision task and repetition priming under both masked and unmasked conditions. The study examined the status of within and between-language cognates and noncognates in Dutch-English bilinguals. Cross-language priming effect was obtained for translation pairs but not for associates. Within and across language, repetition and associative priming effects were found in unmasked condition; however, no cross-language associative priming effect for noncognates was observed under masking condition. The results were an obvious indication of cross-language semantic priming when the primes were not masked. No priming effect was found for associates even under unmasked condition. One year later Sanchez-Casas, Davis \& Garcia-Albea (1992) found the same results.

Another similar study in the area of cross-language experiments carried out under masking paradigm is that of Gollan, Forster, and Frost (1997). The authors argued that conducting the experiment with languages with different scripts would eliminate the orthographic overlapping while trying to obtain pure semantic priming effect. Hebrew and English were the languages under investigation which make use of different alphabets. In the first experiment, they used Hebrew-English pairs to see if they could achieve within-language priming effect. Their second experiment was carried out across the two languages of Hebrew and English with both cognates and noncognates. The authors could obtain both within and across language priming effect for both cognates and noncognates.

In the case of English and Persian languages, Fotovatnia and Taleb (2012) carried out their study using masked priming paradigm to explore lexicon with PersianEnglish bilinguals. The purpose of this study was to investigate the mental representation of cognate and noncognate translation pairs in languages with different scripts (Persian and English). Two groups of Persian-speaking English language learners were tested on cognate and noncognate translation pairs in Persian-English and English-Persian directions with lexical decision task through masked priming. They carried out their study under two experiments. In the first experiment, a group of cognate-noncognate pairs were tested in forward direction (L1L2) with lexical decision task. In this experiment, the primes were in L1 (Persian) and the targets were in L2 (English). In the second experiment, the same cognate- 
noncognate pairs were tested in backward direction (L2-L1) with the same task and the same number of participants. In this experiment, the primes were in L2 (English) and the targets were in L1 (Persian). The findings of the study showed a high level of priming only for cognates with L1 primes. They failed to find any priming effect for non-cognates across Persian and English. They accounted for their findings putting forward the idea by De Groot and Nas (1991); they explained the phenomenon by postulating a bilingual memory with two levels of representations: a lexical representation (i.e., orthographic-phonological) and a conceptual representation (i.e, meaning). Cognate translations share representations at the conceptual level, whereas noncognates do not.

Recently, Javadi (2014) also carried out a study to investigate if bilinguals share semantic features of their L1 and L2 using masked semantic paradigm. The study was in L1-L2 direction. The primes were in L1 (Persian) and the targets were in L2 (English). Target-prime pairs addressed in the study were of four different types; translation equivalent pairs (e.g., جاقو-knife), semantically similar pairs (e.g., سـق door), associatively related pairs (e.g., اســنخوان-dog), and associatively/semantically related pairs (e.g., نمك-pepper). She failed to find any semantic priming effect with the first three types; translation equivalent pairs, semantically similar pairs, and associatively related pairs. But semantically/associatively related pairs were responded faster than unrelated primes. It means she could find semantic priming effect under masked condition for semantically/associatively related pairs.

\subsection{Statement of problem}

One line of psycholinguistic research explores how people represent the two languages i.e., whether they have a separate representation for each language, or a single conceptual representation shared by two languages. Priming experiments have long been considered as a reliable evidence for separate or shared semantic representations. Masked priming, a technique considered to reflect automatic rather than strategic processes, has been reported to be a reliable evidence for models of bilingual shared conceptual representations (Gollan, Forster, \& Frost, 1997, as cited in Javadi, 2014, p. 13). Therefore, the purpose of the present study was to explore whether within-language and cross-language masked priming effect can be achieved using L1 and L2 primes with Persian-English bilinguals.

\subsection{Research questions and hypotheses}

The study was conducted to answer the following questions for which two hypotheses were formulated:

RQ1: Can masked semantic priming effect be achieved using L2 primes for Iranian EFL learners?

Null Hypothesis 1 (Ho1): Masked semantic priming effect cannot be achieved using L2 primes for Iranian EFL learners. 
RQ2: Can masked semantic priming effect be achieved using L1 primes for Iranian EFL learners?

Null Hypothesis 2 (Ho2): Masked semantic priming effect cannot be achieved using L1 primes for Iranian EFL learners.

\section{Method}

\subsection{Design of the study}

The present experimental study draws upon masked priming paradigm as one of the effective techniques for studying bilingual lexicon and lexical access. A study of masked priming using L1 and L2 primes between the two languages of Persian and English was carried out in a series of experiments.

Subjects were tested individually in a quiet room. Presentation of the stimuli and recording of reaction times were made by two laptop computers. In each test, a row of hash marks (\#) was presented for $680-\mathrm{ms}$ on the center of the screen as to indicate where the participants should have expected the words, also to hide the prime. Then, the prime word was presented in the center of the screen for 51-ms. Primes were immediately replaced by the target words. Participants were instructed to press one of the two buttons on the keyboard (right shift key for yes and left shift key for no) to indicate whether the presented word was a word or a nonword. Participants were told that each word would flash on the screen, and they were instructed to respond as quickly and as accurately as possible. It should be noted that the instructions were given in Persian, and reaction times were measured from target onset till participants' responses.

\subsection{Participants}

Sixty male and female undergraduate students studying English Language and Literature at undergraduate level participated in this study. All had at least completed 6 years of formal instruction in English and had learned Persian from childhood as the official language spoken in the country. Most of the participants spoke Azari as their mother tongue. All of the participants had either normal vision or corrected to normal vision, using glasses.

\subsection{Materials}

Two groups of prime-target pairs were created; in group one, primes and targets were in English (e.g., table-chair) and in group two, primes were in Persian but targets were in English (e.g., jی-chair). The materials used in this study were adapted from Chiarello, Burgess, Richards, and Pollock (1990). It should be noted that the materials only included concrete nouns like book, and adjectives and abstract nouns like heat were not addressed by the study. In dealing with the two languages of Persian and English, the components of the pairs were non-cognates. 
Each group consisted of 10 related pairs, and 10 unrelated pairs. In each group, there were 20 pairs of nonwords derived from ARC nonword data base (Rastle, Harrington \& Coltheart, 2002) for the purpose of lexical decision task. Since the words used in the experiment varied from 2 to 7 letters in length, the nonwords were also derived with regard to the same criteria. In other words, each group consisted of 20 words and 20 nonwords as for the yes answers to be equal to no answers. Each participant received 40 trials per group, a total of 80 trials in 2 groups. All of the participants received the items in the same order. The whole session lasted approximately 10 minutes. Reaction times (RTs) were measured using DMDX software developed by Forster and Davis (1984).

In order to make sure that the participants in the study are balanced bilinguals a proficiency test of TOEFL was given. Afterwards, the students were met individually to make an appointment for the test. Besides, participants filled in a questionnaire about their linguistic background.

\subsection{Data analysis}

At first incorrect answers were excluded from data analysis. RTs below 300-ms and above 1800-ms were also excluded from data analysis since they were either late responses to a previous item or no responses in the allowed time. It was done in order to moderate the influence of outliers. The data were analyzed by SPSS version 20 . Two within group T-test were carried out on the data in order to compare the RTs of related vs. unrelated pairs.

\section{Results}

\subsection{Masked experiment with L2 primes}

In this group, within related and unrelated word pairs, 176 trials were wrong answers and 13 trials were outliers, so they were excluded from the total data which was 2400 trials. The analysis was carried out on 2211 trials. Mean latencies for correct responses were calculated across items. The mean reaction time in related condition was 592.2736. However, in unrelated condition it was 581.6473. A summary of mean RTs for this group appears in Table 1.

Table 1: Mean RTs for masked experiment with L2 primes

\begin{tabular}{lllll}
\hline & Grouping & $\mathrm{N}$ & Mean & Std. Deviation \\
\hline \multirow{3}{*}{ Reaction time } & Related condition & 460 & 592.27365 & 175.595768 \\
& Unrelated condition & 551 & 581.64737 & 137.361623 \\
\hline
\end{tabular}

The mean RTs for related and unrelated pairs were different, T-test based on participants RTs was carried across two groups of items to show if this difference is significant or not. The main effect of priming was insignificant in masked experiment using L2 primes (sig. .517 > .05) as illustrated in Table 2. 
Table 2: T-Test results for masked experiment with L2 primes

\begin{tabular}{lcclllll}
\hline & $\mathrm{N}$ & Mean & $\begin{array}{l}\text { Mean } \\
\text { Difference }\end{array}$ & $\begin{array}{l}\text { Standard } \\
\text { Dev. }\end{array}$ & $\mathrm{t}$ & $\mathrm{df}$ & Significance \\
\hline Related condition & 460 & 592.27 & 5.313142 & 175.59 & .649 & 459 & .517 \\
\hline Unrelated condition & 551 & 581.64 & -5.313142 & 137.36 & -.908 & 550 & .364 \\
\hline
\end{tabular}

Based on the findings, the null hypothesis was confirmed and the alternative hypothesis was rejected. Masked semantic priming effect cannot be achieved using L2 primes for Iranian EFL learners.

\subsection{Masked Experiment with L1 primes}

In this condition, i.e., within related and unrelated word pairs, 88 trials were wrong answers and 6 trials were outliners, so there were excluded from the total data and the analysis was carried out on 2306 remaining trials. The mean reaction time in related condition was 555.8116 and in unrelated condition 554.1198. A summary of mean RTs for this group appears in Table 3.

Table 3: Mean RTs for masked experiment with L1 primes

\begin{tabular}{lllll}
\hline & Grouping & N & Mean & Std. Deviation \\
\hline \multirow{2}{*}{ Reaction time } & Related condition & 552 & 555.81165 & 109.995699 \\
& Unrelated condition & 554 & 554.11984 & 109.140494 \\
\hline
\end{tabular}

As for the previous group, a T-test based on participants RTs was carried across two groups of items to show if this difference is significant or not. The main effect of priming was insignificant in masked experiment using L1 primes (sig. .857 > .05) as illustrated in Table 4.

Table 4: T-Test results for masked experiment with L1 primes

\begin{tabular}{llllllll}
\hline & $\mathrm{N}$ & Mean & $\begin{array}{l}\text { Mean } \\
\text { Difference }\end{array}$ & $\begin{array}{l}\text { Standard } \\
\text { Dev. }\end{array}$ & $\mathrm{t}$ & $\mathrm{df}$ & Significance \\
\hline Related condition & 552 & 555.81 & .845904 & 109.99 & .181 & 551 & .857 \\
\hline Unrelated condition & 554 & 554.11 & -.845907 & 109.14 & -.182 & 553 & .855 \\
\hline
\end{tabular}

According to the findings, the null hypothesis was confirmed and the alternative hypothesis was rejected. Masked semantic priming effect cannot be achieved using L1 primes for Iranian EFL learners.

\section{Discussion}

The description of representation of languages in a bilingual mind has always been one of the challenging issues for psychologist. Questions like whether information for two languages is stored in one single lexicon or two separate lexicons, and the way it is accessed has been addressed by researchers interested in language processing research.

Particular interest has been shown by psycholinguists by exploring bilingual lexicons, using priming effect. Although there are various studies addressing the issue, the cross-language research on languages with different scripts needs further research. Since Persian and English make use of completely different scripts, the two 
languages seemed to be good candidates for exploring under masked priming paradigm. The present study was an attempt to investigate bilingual mental lexicon and mental access.

As mentioned before, in order to investigate the status of words from two different languages in bilingual mental lexicon, one of the efficient ways would be to look for priming effect across languages. However, masked priming technique rather than visible priming technique is considered to yield more pure effects since it eliminates bilinguals' strategic use of the primes.

The hypothesis was that whether semantic priming effect would be achieved with L1 and L2 primes under masked technique. However, the results indicated that responses for unrelated pairs were faster than responses for related pairs. And the priming effect was found to be insignificant in both conditions.

According to previous studies, cross-language semantic priming studies which were conducted under masked conditions have yielded rather varied results. There are reports of significant priming effect and also reports of null effect in different studies.

For example, in the case of Persian and English languages, Fotovatnia and Taleb (2012) investigated semantic priming effect with Persian-English bilinguals under masked paradigm with cognates and noncognates. However, they could not find a significant priming effect for noncognates. Authors attributed the lack of noncognate priming to lower proficiency of their participants. They also suggested that noncognates do not share representations at the conceptual level according to De Groot and Nas (1991).

In a recent study, Javadi (2014) investigated priming effect with Persian-English bilinguals under masked paradigm within four types of pairs. These four pairs were translation equivalent pairs, semantically similar pairs, associatively related pairs, and associatively/semantically related pairs. The author failed to find priming effect for translation equivalent pairs, semantically similar pairs, and associatively related pairs. She could find priming effect only for associatively/semantically related pairs.

The present study failed to find priming effect with Persian-English bilinguals under masked paradigm using L1 and L2 primes. As for this, one may suggest that since different scripts activate different lexical levels i.e., nonselective access, as predicted by Revised Hierarchical Model (RHM), words from L1 may fail to prime L2 words. What's more, according to negative priming idea, which was first proposed by Bijeljac-babic, Biardeau, and Grainger (1997), being exposed to different words activates lexical representations from both languages and it makes the processing more time taking.

Another factor which leads to lack of priming could be related to participants and it can be interpreted in terms of lower levels of proficiency in the L2. Also when the participants are late bilinguals the link between the lexical and conceptual level is not so strong to allow semantic priming. Revised Hierarchical Model (RHM) assumes the same conceptual level for the two languages in a bilingual memory (French \& Jacquet, 
2004), and the strength is varied for different bilinguals and different languages. As the finding of the present study suggest this link strength in languages with different scripts, which allows direct access to the conceptual level and consequently leads to activation of shared semantic features, needs to be strengthened by either higher proficiency level or early bilingualism.

Moreover, in this study, all words were non-cognates in Persian and English. According to De Groot and Nas (1991), cognate words share representations at the conceptual level, whereas noncognates do not share representations at the conceptual level. Other studies also confirmed lack of significant noncognate priming (GarcíaAlbea, Sánchez-Casas, Bradley \& Forster, 1985; García-Albea, Sánchez-Casas, \& Igoa, 1998; Grainger \& Frenck-Mestre, 1998).

\subsection{Implications of the sudy}

The present study explored the mental representation of words in the mind of Persian/English bilinguals to refine our understanding of lexical acquisition and processing in L1 and L2. Such understanding contributes to the models that explore the structure of mental cognitive structure that is in charge of storage and processing of information at the theoretical level and the effective design and implementation of instructional materials at the pedagogical level. As Brunning, Schraw, and Ronning (1999: p. iv) put it, "there are very few educational decisions to which the cognitive issues of memory, thinking, and problem-solving are not relevant" (as cited in Fotovaynia \& Taleb, 2012: p. 38). The findings of the present study suggest that using related words between languages in the process of vocabulary teaching is more useful in higher proficiency levels.

\section{Conclusion}

In this study, it was intended to explore the idea whether semantic priming effect could be achieved for semantically related pairs, using L1 and L2 primes, under masked paradigm. However, semantic priming effect was not obtained in different conditions of the study. So we could conclude that, masked semantic priming effect cannot be achieved using L2 or L1 primes for Iranian EFL learners. At least in languages with different scripts, higher proficiency level would be needed to access conceptual level in the mind and activate shared semantic features between languages and achieve priming effects.

\section{References}

Bijeljac-Babic, R., Biardeau, A., \& Grainger, J. (1997). Masked orthographic priming in bilingual word recognition. Memory \& Cognition, 25(4), 447-457.

Bourassa, D. C., \& Besner, D. (1998). When do nonwords activate semantics? Implications for models of visual word recognition. Memory \& Cognition, 26, 61-74.

Chen, H. C., \& Ng, M. L. (1989). Semantic facilitation and translation priming effects in Chinese-English bilinguals. Memory \& Cognition, 17, 454-462.

Chen, B., Zhou, H., Gao, Y. and Dunlap S. (2014). Cross-Language translation priming asymmetry with Chinese-English bilinguals: A test of the sense model. Journal of Psycholinguistic Research. 43, 225-240. 
Chiarello, C., Burgess, C., Richards, L., \& Pollock, A. (1990). Semantic and associative priming in the cerebral hemispheres: Some words do, some words don't . . .sometimes, some places. Brain and Language, 38, 75-104.

De Groot, A. M. (2011). Language and cognition in bilinguals and multilinguals: An introduction. New York, NY, US: Psychology Press.

De Groot, A. M. B., \& Nas, G. L. (1991). Lexical representation of cognates and non-cognates in compound bilinguals. Journal of Memory and Language, 30, 90-123.

Field, J. (2003). Psycholinguistics: A resource book for students. London: Routledge.

Field, J. (2004). Psycholinguistics: the key concepts. London: Routledge.

Fischler, I. (1977). Semantic facilitation without association in a lexical decision task. Memory \& Cognition, 5, 335-339.

Forster, K. L., \& Davies, C. (1984). Repetition priming and frequency attenuation in lexical access. Journal of Experimental psychology: Learning, Memory, and Cognition, 10, 680-698.

Fotovatnia, Z. \& Taleb, F. (2012). Masked noncognate priming across Farsi and English. Journal of Teaching Language Skills, 4(1), 25-48.

García-Albea, J.E., Sánchez-Casas, R.M., Bradley, D.C., \& Forster, K.I. (1985, November) Cross-language priming effects in bilingual word recognition. Paper presented at the meeting of the Fifth Australian Language Conference, Melbourne, Australia.

Gollan, T. H., Forster, K. I., \& Frost, R. (1997). Translation priming with different scripts: Masked priming with cognates and noncognates in Hebrew-English bilinguals. Journal of Experimental Psychology: Learning, Memory, and Cognition, 23, 1122-1139.

Grainger, J., \& Frenck-Mestre, C. (1998). Masked priming by translation equivalents in proficient bilinguals. Language and Cognitive Processes, 13(6), 601-623.

Javadi, Sh. (2014). Masked associative/semantic priming effects across languages with Iranian EFL learners. Unpublished Master's thesis: University of Tabriz.

Jiang, N., \& Forster, K. I. (2001). Cross-language priming asymmetries in lexical decision and episodic recognition. Journal of Memory \& Language, 44(1), 32-51.

Keatley, C., \& de Gelder, B. (1992). The bilingual primed lexical decision task: Crosslanguage priming disappears with speeded responses. European Journal of Cognitive Psychology, 4, 273-292.

Kotz, S. A. (2001). Neurolinguistic evidence for bilingual language representation: A comparison of reaction times and event-related brain potentials. Bilingualism: Language and Cognition, 4, 143-154.

Kotz, S. A. \& Elston-Guttler, K. E. (2004). The role of proficiency on processing categorical and associative information in the L2: Reaction times and event related potentials. Journal of Neurolinguistics, 17, 215-235.

Merikle, P. M. (2000). Subliminal perception. In Kazdin, A. E. (Eds.), Encyclopedia of Psychology (Vol. 7, pp. 497-499). New York: Oxford University Press.

Meyer, D. E., \& Schavaneveldt, R. W. (1971). Facilitation in recognizing pairs of words: Evidence of a dependence between retrieval operations. Journal of Experimental Psychology, 90, 227-234.

Perea, M., Dunabeitia, J. A., \& Carreiras, M. (2008). Masked associative/semantic priming effects across languages with highly proficient bilinguals. Journal of Memory and Language, 58, 916-930.

Rastle, K., Harrington, J., \& Coltheart, M. (2002). 358,534 nonwords: the ARC Nonword Database. The Quarterly Journal of Experimental Psychology A, 55(4), 1339-62.

Sanchez-Casas, R. M., Davis, C. W., \& Garcia-Albea, J. E. (1992). Bilingual lexical processing: Exploring the cognate/non-cognate distinction. European Journal of Cognitive Psychology Special Issue: Multilingual community, 4(4), 293-310.

Sánchez-Casas, R, Ferré, P., Demestre, J., García-Chico, T. \& García-Albea, JE. (2012). Masked and unmasked priming effects as a function of semantic relatedness and associative strength. Span J Psychol, 15(3), 891-900. 
Scaborough, D. L., Gerard, L. \& Corteses, C. (1984). Independence of lexical accessing in bilingual word recognition. Journal of Verbal Learning \& Verbal Behavior, 23, 84-99.

Schoonbaert, S., Duyck, W., Brysbaert, M. \& Hartsuiker, R. J. (2009). Semantic and translation priming from a first language to a second and back: Making sense of the findings. Memory and Cognition, 37, 569-586.

Schvaneveldt, R. W. \& Meyer, D. E. (1973). Retrieval and comparison processes in semantic memory. In S. Kornblum (Ed.), Attention and performance IV (pp. 395-409). New York, NY: Academic Press.

Williams, J. N. (1994). The relationship between word meanings in the first and second language: Evidence for a common, but restricted, semantic code. European Journal of Psychology, 6, 195-220.

Zhao, X., Li, P., Liu, Y., Fang, X. \& Shu, H. (2011). Cross-Language priming in ChineseEnglish bilinguals with different second language proficiency levels. In L. Carlson, C. Hölscher, \& T. Shipley (Eds.), Proceedings of the 33rd annual conference of the cognitive science society (pp. 801-806). Austin, TX: Cognitive Science Society.

\section{Copyrights}

Copyright for this article is retained by the author(s), with first publication rights granted to the Journal.

This is an open-access article distributed under the terms and conditions of the Creative Commons Attribution license (CC BY-NC-ND) (http://creativecommons.org/licenses/by-nc-nd/4.0/). 